\title{
How much esmolol was administered?
}

\author{
Mehmet S. Ozcan, MD
}

Received: 1 April 2012/Accepted: 3 May 2012/Published online: 18 May 2012

(C) Canadian Anesthesiologists' Society 2012

\section{To the Editor,}

In their recent article, Lopez-Alvarez et al. compared an esmolol infusion $v s$ ketamine-remifentanil combination for their effects on postoperative analgesia. ${ }^{1}$ I read the article with great interest, but I am confused about the esmolol dosing regimen that is reported. In the methods section, the dose of esmolol was reported as $0.5 \mathrm{mg} \cdot \mathrm{kg}^{-1} i v$ bolus, followed by a continuous infusion titrated from 5-15 $\mu \mathrm{g} \cdot \mathrm{kg}^{-1} \cdot \mathrm{min}^{-1}$ to maintain the patient's mean arterial pressure and heart rate within $20 \%$ of respective baseline values. Reviewing Table 1 of the article, the mean total esmolol dose administered was $5.2 \mathrm{mg} \cdot \mathrm{kg}^{-1}$, whereas the mean duration of anesthesia was $64 \mathrm{~min}$. Mathematically, $4.7 \mathrm{mg} \cdot \mathrm{kg}^{-1}$ of the mean total dose had to be given as an infusion (since the bolus dose was $0.5 \mathrm{mg} \cdot \mathrm{kg}^{-1} i v$ in all patients). Therefore, even had the patient received the maximum stated dose of esmolol (i.e., $15 \mu \mathrm{g} \cdot \mathrm{kg}^{-1} \cdot \mathrm{min}^{-1}$ ) for the entire duration of anesthesia, this would have resulted in a mean total dose of esmolol of only $0.96 \mathrm{mg} \cdot \mathrm{kg}^{-1}$. Adding the bolus dose would then bring the total dose to $1.46 \mathrm{mg} \cdot \mathrm{kg}^{-1}$. Accordingly, there appears to be a considerable discrepancy between the esmolol dosing according to the methods (1.46 mg $\cdot \mathrm{kg}^{-1}$, calculated for mean anesthetic duration assuming the maximum infusion rate) and the results $\left(5.2 \mathrm{mg} \cdot \mathrm{kg}^{-1}\right)$. I would be curious to hear from the authors as to whether they used a much bigger dose range of esmolol or whether they miscalculated the total esmolol dose reported in Table 1 of their article.

Conflicts of interest None declared.

M. S. Ozcan, MD ( $\square)$

University of Illinois at Chicago, Chicago, IL, USA

e-mail: msozcan@gmail.com

\section{Reference}

1. Lopez-Alvarez S, Mayo-Moldes M, Zaballos M, Iglesias BG, Blanco-Davila $R$. Esmolol versus ketamine-remifentanil combination for early postoperative analgesia after laparoscopic cholecystectomy: a randomized controlled trial. Can J Anesth 2012; 59: 442-8.

\section{Reply}

We sincerely thank Dr. Ozcan for his interest in our article and welcome the opportunity to clarify the esmolol dosing regimen that we reported. ${ }^{1}$ We had originally planned to use a bolus dose of esmolol $0.5 \mathrm{mg} \cdot \mathrm{kg}^{-1} i v$ to be followed by a continuous infusion titrated according to patient requirements, at a rate from $5-15 \mu \mathrm{g} \cdot \mathrm{kg}^{-1} \cdot \mathrm{min}^{-1}$, to maintain mean arterial pressure and heart rate within $20 \%$ of the patients' respective baseline values. However, soon after initiation of the study, we found that the dosing regimen initially planned made it impossible to achieve and maintain the desired hemodynamic goals. This was explained in the discussion section of our article, as we had to administer a much higher dose of esmolol [mean (standard deviation) dose of $382(255) \mathrm{mg}$, equivalent to $\left.5.2 \mathrm{mg} \cdot \mathrm{kg}^{-1}\right]$. This dose was similar to that reported by Chia et al., who administered a mean esmolol dose of 375.4 (143.4) $\mathrm{mg}$, which showed an opioid-sparing effect of this drug. ${ }^{2}$ The opioid -sparing effect of esmolol has been described previously within this dose range in two other studies. ${ }^{3,4}$ In contrast, Collard et al. used lower doses of esmolol (approximately $94 \mathrm{mg}$ ). In their study, both esmolol and remifentanil were titrated to maintain a heart rate within $\pm 20 \%$ of each subject's baseline value. In our view, this methodological distinction probably accounts for the different doses of esmolol and remifentanil in the 
Collard et al. study compared with ours $(1.3 \mathrm{vs}$ $5.2 \mathrm{mg} \cdot \mathrm{kg}^{-1}$; and 7.6 vs $21 \mu \mathrm{g} \cdot \mathrm{kg}^{-1}$, respectively). ${ }^{1,5} \mathrm{We}$ sincerely hope that this explanation resolves any confusion regarding the doses of esmolol administered in our study, as reflected in Table 1 of the article.

Conflicts of interest None declared.

\section{References}

1. Lopez-Alvarez S, Mayo-Moldes M, Zaballos M, Iglesias BG, Blanco-Davila R. Esmolol versus ketamine-remifentanil combination for early postoperative analgesia after laparoscopic cholecystectomy: a randomized controlled trial. Can J Anesth 2012; 59: 442-8.

2. Chia YY, Chan MH, Ko NH, Liu K. Role of beta-blockade in anaesthesia and postoperative pain management after hysterectomy. Br J Anaesth 2004; 93: 799-805.
3. Koivusalo AM, Scheinin M, Tikkanen I, et al. Effects of esmolol on haemodynamic response to $\mathrm{CO} 2$ pneumoperitoneum for laparoscopic surgery. Acta Anaesthesiol Scand 1998; 42: 510-7.

4. Johansen JW, Schneider G, Windsor AM, Sebel PS. Esmolol potentiates reduction of minimum alveolar isoflurane concentration by alfentanil. Anesth Analg 1998; 87: 671-6.

5. Collard V, Mistraletti G, Taqi A, et al. Intraoperative esmolol infusion in the absence of opioids spares postoperative fentanyl in patients undergoing ambulatory laparoscopic cholecystectomy. Anesth Analg 2007; 105: 1255-62.

Matilde Zaballos, MD, PhD

Hospital Universitario Gregorio Marañón, Madrid Universidad Complutense De Madrid, Madrid

Monica Mayo-Moldes, MD

Hospital Meixoiro, Complexo Hospitalario Universitario de Vigo, Vigo

Servando López-Álvarez, MD

Hospital Abente y Lago, Complexo Hospitalario Universitario, A Coruña, Spain 